Categoria

Trabalho Acadêmico / Artigo Completo

\title{
AVALIAÇÃO DA ADEQUAÇÃO DA RESERVA LEGAL NO MUNICÍPIO DE LAVRAS - MG
}

\author{
Ana Luisa Alves Cabral ${ }^{1}$
}

Luiz Otávio Moras Filho²

\section{Luís Antônio Coimbra Borges ${ }^{3}$}

\begin{abstract}
RESUMO: Foi realizado um levantamento no Cartório de Registro de Imóveis de todas as propriedades rurais registradas entre os anos 2000 e 2010 do município de Lavras/MG com o objetivo de conhecer o total de propriedades, assim como o percentual destas que possuem a averbação da Reserva Legal. A partir desses dados, foram analisadas algumas propriedades com o auxílio de imagens de satélite a fim de se avaliar a situação da reserva legal que havia sido averbada no cartório. O levantamento revelou um baixo percentual de averbação de reserva legal no município (31,5\%). Os estudos das imagens das propriedades revelaram inúmeras irregularidades, como a exploração inadequada ou até mesmo a inexistência da reserva legal. O trabalho mostrou uma grande ineficiência na fiscalização das propriedades rurais do município e que a biodiversidade está sendo prejudicada pela falta de áreas preservadas.
\end{abstract}

Palavras-chave: Reserva Legal. Código Florestal. Conservação Ambiental.

\footnotetext{
${ }_{1}^{1}$ Bacharel em Engenharia Florestal, UFLA. analuisa.cabral@outlook.com.

${ }^{2}$ Bacharel em Engenharia Florestal, UFLA. lomf_22@hotmail.com.

${ }^{3}$ Professor Adjunto do Departamento de Ciências Florestais, UFLA. luis.borges@dcf.ufla.br.
} 


\section{INTRODUÇÃO}

A conservação, em áreas de propriedade rural, de fragmentos de florestas e outros tipos de vegetação são essenciais para proteger, ainda que minimamente, a fauna e a flora originais de cada região. Sendo assim, a atual resolução do Código Florestal (Lei no 12,651/12), junto da MP no 571/12, trazem mecanismos preciosos para assegurar essa conservação: as áreas de preservação permanente e as reservas legais.

De acordo com o CONAMA (2002), a reserva legal é uma área localizada no interior de uma propriedade rural, excetuada a de preservação permanente, necessária para o uso sustentável dos recursos naturais, a conservação e reabilitação dos processos ecológicos, a conservação da biodiversidade, bem como a proteção de fauna e flora nativas.

A reserva legal, segundo CAMPOS et al. (2002), é considerada uma área plausível de uso, desde que não se pratique o corte raso; com isso, além de seu papel conservacionista, também exerce função no fornecimento de bens econômicos de forma sustentável.

A ação coercitiva por parte do Estado não tem se mostrado, porém, suficiente para garantir o cumprimento da legislação ambiental no que diz respeito às áreas de Reserva Legal. Mesmo cientes de sua importância ambiental e potencial econômico, ainda existem barreiras culturais, normativas, técnicas e econômicas para que tais exigências legais sejam cumpridas pelos agricultores. No caso de pequenos produtores familiares, esse problema tende a se agravar, em razão da pouca disponibilidade de área para o cultivo e sobrevivência da família (adaptado de RAMOS FILHO e FRANCISCO, 2004).

Impedir e reverter o processo de destruição do meio ambiente implica, portanto, adotar soluções econômicas e práticas agrícolas que permitam aos produtores melhorarem suas condições de vida. A reserva legal apresenta um enorme potencial como fonte de soluções alternativas para os problemas enfrentados, permitindo, principalmente aos pequenos produtores, retornos econômicos e maior conservação dos recursos naturais (MONTAGNINI, 1992; DUBOIS et al., 1996).

Tendo em vista a importância que representam as áreas de Reserva Legal, gera-se a necessidade de estudos sobre as mesmas a fim de conhecer e avaliar a situação em que se encontram e se o seu papel conservacionista está sendo cumprido de acordo com a legislação. 


\section{OBJETIVOS}

Quantificar e analisar as propriedades com a Reserva Legal devidamente averbadas entre os anos de 2000 e 2010;

Conhecer a real situação do cumprimento da Reserva Legal de algumas propriedades demonstrativas utilizando-se de imagens de satélite;

Propor formas de regularizar essa situação no município de Lavras/MG.

\section{REFERENCIAL TEÓRICO}

As áreas protegidas são espaços territorialmente demarcados cuja principal função é a conservação e, ou, a preservação de recursos, naturais e, ou, culturais, a elas associados (MEDEIROS, 2003).

Proteger áreas no interior das propriedades rurais é muito importante para conservar a biodiversidade local. As ferramentas utilizadas pelo poder público para este fim foram definidas pelo Código Florestal Brasileiro (Lei 4.771/65) ao instituir as áreas de preservação permanente e as reservas legais, que devem ser obrigatoriamente instituídas em toda propriedade rural.

Desde a sua vigência, o código vem sofrendo inúmeras alterações, por meio de leis, decretos e medidas provisórias, que demonstram a dificuldade dos legisladores em conciliar os interesses dos diversos atores envolvidos no assunto (SERAFINI, 2011).

Depois de um longo percurso, iniciado com o reconhecimento de espaços territoriais especialmente protegidos pela Constituição Federal, passando pela publicação do Decreto no 23.793/34, onde foi instituído o primeiro "Código Florestal Brasileiro", seguido da lei $n^{\circ} 4.771 / 65$ que instituiu o "Novo Código Florestal", reeditado por diversas Medidas Provisórias, como a MP nº 2.166-67/0, a legislação que trata dessas áreas protegidas, bem como de diversas normas ambientais, ganhou uma nova resolução sancionada pela Presidenta Dilma Rousseff, no dia 25 de maio de 2012.

As áreas de Reserva Legal são aquelas delimitadas no interior da propriedade, excetuada a APP, representativas do ecossistema no qual estão inseridas e são passíveis de intervenção, mediante plano de manejo aprovado pelo órgão ambiental competente (Adaptado de BORGES, 2011).

A delimitação dessas áreas é tipificada no Art. 12 do Código Florestal, como pode ser observado no transcrito abaixo: 
Art. 12. Todo imóvel rural deve manter área com cobertura de vegetação nativa, a título de Reserva Legal, sem prejuízo da aplicação das normas sobre as Áreas de Preservação Permanente, observados os seguintes percentuais mínimos em relação à área do imóvel:

I - localizado na Amazônia Legal:

a) $80 \%$ (oitenta por cento), no imóvel situado em área de florestas;

b) $35 \%$ (trinta e cinco por cento), no imóvel situado em área de cerrado;

c) $20 \%$ (vinte por cento), no imóvel situado em área de campos gerais;

II - localizado nas demais regiões do País: 20\% (vinte por cento). (BRASIL, 2012)

Quanto a sua localização, é definido pelo art. 14 da mesma lei que:

Art. 14. A localização da área de Reserva Legal no imóvel rural deverá levar em consideração os seguintes estudos e critérios:

I - o plano de bacia hidrográfica;

II - o Zoneamento Ecológico-Econômico;

III - a formação de corredores ecológicos com outra Reserva Legal, com Área de Preservação Permanente, com Unidade de Conservação ou com outra área legalmente protegida;

IV - as áreas de maior importância para a conservação da biodiversidade; e

$\mathrm{V}$ - as áreas de maior fragilidade ambiental. (BRASIL, 2012)

Porém, mesmo diante de mudanças favoráveis á alocação da $\mathrm{RL}$ na propriedade rural, ainda existiam discussões fundamentadas no direito constitucional ao uso da propriedade, visto que foi limitado o uso de parte do imóvel. Sendo assim, foram estabelecidos critérios para permitir o cômputo das APP no calculo do percentual de $R L$, desde que permaneça inalterado o regime de proteção da APP.

A nova resolução do Código Florestal restringiu as formas de uso da $R L$ e ordenou a suspensão imediata das atividades em Área de Reserva Legal desmatada irregularmente após 22 de julho de 2008, além da recuperação dessas áreas em até dois anos a partir da publicação da lei.

Ainda se tratando de pontos benéficos aos produtores rurais, foram permitidas maneiras de se manejar as $\mathrm{RL}$, conforme os artigos citados a seguir:

Art. 20. No manejo sustentável da vegetação florestal da Reserva Legal, serão adotadas práticas de exploração seletiva nas modalidades de manejo sustentável sem propósito comercial para consumo na propriedade e manejo sustentável para exploração florestal com propósito comercial.

Art. 21. É livre a coleta de produtos florestais não madeireiros, tais como frutos, cipós, folhas e sementes, devendo-se observar:

I - os períodos de coleta e volumes fixados em regulamentos específicos, quando houver;

II - a época de maturação dos frutos e sementes;

III - técnicas que não coloquem em risco a sobrevivência de indivíduos e da espécie coletada no caso de coleta de flores, folhas, cascas, óleos, resinas, cipós, bulbos, bambus e raízes. 
Art. 22. O manejo florestal sustentável da vegetação da Reserva Legal com propósito comercial depende de autorização do órgão competente e deverá atender as seguintes diretrizes e orientações:

I - não descaracterizar a cobertura vegetal e não prejudicar a conservação da vegetação nativa da área;

II - assegurar a manutenção da diversidade das espécies;

III - conduzir o manejo de espécies exóticas com a adoção de medidas que favoreçam a regeneração de espécies nativas.

Art. 23. O manejo sustentável para exploração florestal eventual sem propósito comercial, para consumo no próprio imóvel, independe de autorização dos órgãos competentes, devendo apenas ser declarados previamente ao órgão ambiental a motivação da exploração e o volume explorado, limitada a exploração anual a 20 (vinte) metros cúbicos. (BRASIL, 2012)

Não obstante, o art. 66 ainda determina que o possuidor de imóvel rural que detinha, em 22 de julho de 2008, área de Reserva Legal em extensão inferior ao estabelecido no art. 12, poderá regularizar sua situação, independentemente da adesão ao Programa de Regularização Ambiental (PRA), adotando as seguintes alternativas, isolada ou conjuntamente: recompor a $R L$; permitir a regeneração natural da vegetação na área de $R L$; compensar a $R L$.

Contudo, não há como negar, do ponto de vista ruralista, a importância dessas modificações para assegurar a exploração econômica da propriedade de forma mais plena possível. Porém, uma grande discussão se forma com os ambientalistas, pois nota-se que essas novas formas de exploração da $R L$ não se encontram em consonância ao equilíbrio ambiental. Existem inclusive propostas de alteração da MP 571 no senado, onde se busca um consenso até então não consolidado na aprovação da nova lei florestal.

\section{MATERIAL E MÉTODOS}

Este trabalho baseou-se em pesquisas bibliográficas e estudos de casos. A pesquisa bibliográfica pode ser considerada o primeiro passo da pesquisa científica, buscando harmonizar os vários pontos de vista, gerando uma visão sensata e útil, sob o aspecto informativo, do problema em estudo (BORGES, 2009).

O estudo de caso se deu a partir do levantamento das áreas rurais do município de Lavras, Minas Gerais, realizado no Cartório de Registro de Imóveis. Foi realizado o levantamento das propriedades registradas entre os anos de 2000 e 2010, durante os meses de março a junho de 2011. As propriedades levantadas foram divididas em classes de acordo com suas áreas como mostra a Tabela 01. 
Tabela 01. Divisão das propriedades em classes

\begin{tabular}{cc}
\hline CLASSE & ÁREA (ha) \\
\hline I & 0 a 120 \\
II & $>120$ \\
\hline
\end{tabular}

As classes foram assim divididas devido à definição contida na alínea $\mathrm{V}$, artigo terceiro do Código Florestal, que considera a pequena propriedade como toda propriedade que possua até 04 módulos fiscais, o que implica para o município de Lavras em uma área de até 120 hectares.

Com os dados levantados foi possível fazer uma análise da situação das propriedades em relação ao atual Código Florestal, assim como prever os impactos decorrentes da alteração do Código Florestal em tramitação sobre a adequação ambiental.

A partir dos dados coletados no cartório, foi selecionada uma propriedade por classe e suas coordenadas geográficas para que fosse feita análise da real situação em que as áreas de Reserva Legal se encontram. Tal estudo foi feito com auxílio de imagens de satélites georreferenciadas retiradas do Google Earth.

Foi feito o reconhecimento do estado de conservação das propriedades selecionadas por meio de análise visual.

\section{RESULTADOS E DISCUSSÃO}

\subsection{Levantamento das Propriedades Rurais de Lavras}

A partir do levantamento realizado no Cartório de Registro de Imóveis do município de Lavras - MG foram encontradas um total de 1625 propriedades registradas entre os anos 2000 e 2010. Entres estas apenas 513 possuíam reserva legal devidamente averbada, perfazendo um total de $31,5 \%$.

De acordo com o Censo Demográfico 2010 realizado pelo IBGE existem em Lavras 2.893 endereços rurais. Assim, é possível afirmar que foram levantadas $56,17 \%$ das propriedades rurais do município. As $43,83 \%$ propriedades restantes que não foram analisadas tiveram suas matrículas registradas antes de 2000. A regularização das propriedades à época não exigia a regularização da $\mathrm{RL}$, ou se exigia, era com menos pressão do que na última década, logo, é possível que a situação das propriedades não levantadas seja ainda pior. 
Tabela 02. Resultado das propriedades divididas em classes

\begin{tabular}{cccc}
\hline CLASSES & $\begin{array}{c}\text { TOTAL DE } \\
\text { PROPRIEDADES }\end{array}$ & $\begin{array}{c}\text { TOTAL DE } \\
\text { PROPRIEDADES } \\
\text { COM RL }\end{array}$ & RL (\%) \\
\hline Classe I & 1595 & 495 & 31,03 \\
Classe II & 30 & 18 & 60,00 \\
\hline
\end{tabular}

A primeira classe obteve nitidamente um percentual mais baixo, mostrando assim que as pequenas propriedades possuem menor índice de averbação. Isso mostra como a pequena propriedade familiar, deveria ser estimulada a conservar e recuperar suas reservas legais de forma a auferir rendimentos mediante o uso sustentável da floresta. Esse incentivo poderia vir por meio de políticas de estímulo ao uso sustentável da reserva legal (IPEA, 2011).

A averbação da $R L$ da pequena propriedade é gratuita, como já citado e o Poder Público deve prestar apoio técnico e jurídico sempre que necessário. Além disso, a pequena propriedade também tem o direito de computar do plantio de árvores frutíferas na área da RL.

Diferentemente da pequena propriedade, a última classe obteve mais da metade das propriedades com averbação da reserva legal. Muitos financiamentos privados exigem que a propriedade esteja de acordo com a legislação, e são as propriedades de grande porte o objeto desses financiamentos. Logo, se esta exigência também fosse feita ao pequeno produtor, talvez os índices de averbação da $\mathrm{RL}$ aumentassem consideravelmente.

Com base nas informações do Sistema Nacional de Cadastro Rural (SNCR), gerenciado pelo Instituto Nacional de Colonização e Reforma Agrária (INCRA), observa-se que os minifúndios representam $65 \%$ do total de imóveis rurais do país e detêm apenas $8 \%$ da área. Por outro lado, as grandes propriedades, ocupam 56\% da área e representam 3\% dos imóveis rurais.

Com base nos dados levantados o município de Lavras está muito próximo dos valores nacionais, como mostra a Tabela 03. A classe I apresenta o maior número de propriedades, mas em termos de área ela representa apenas $36,16 \%$, enquanto a classe III com apenas 30 propriedades representa mais de $60 \%$ da área ocupada. 
Tabela 03. Área total de cada classe e suas respectivas porcentagens.

\begin{tabular}{ccc}
\hline CLASSE & ÁREA TOTAL (ha) & \% ÁREA \\
\hline I & $21.724,03$ & 36,16 \\
II & $38.352,99$ & 63,84 \\
TOTAL & $60.077,02$ & 100 \\
\hline
\end{tabular}

A área das propriedades também foi analisada a fim de se conhecer a área total preservada, a Tabela 04 traz estes resultados que mostram que apenas 4,26\% da área destas propriedades são destinadas a conservação na forma de RL.

Tabela 04. Área preservada na forma de Reserva Legal.

\begin{tabular}{ccc}
\hline & Propriedades & Propriedades com RL \\
\hline Número & 1625 & 513 \\
Área Total (Ha) & $60.077,02$ & $2.561,67$ \\
\hline
\end{tabular}

5.2. Análise das propriedades com uso de imagens de satélite

Para se conhecer a situação das propriedades registradas no município de Lavras, escolheu-se uma propriedade de cada classe de forma aleatória. Todas estas propriedades possuíam suas coordenadas geográficas em seu registro, assim como a averbação da Reserva Legal. A Tabela 05 traz as áreas advindas do cartório destas propriedades.

Tabela 05. Área das propriedades analisadas

\begin{tabular}{ccc}
\hline & Propriedade 1 & Propriedade 2 \\
\hline Classe & Classe I & Classe II \\
Área & 10,72 & 125,26 \\
\hline
\end{tabular}




\section{-

A partir das coordenadas geográficas, foi possível localiza-las no globo com o auxilio das imagens do Google Earth. A Figura 01 mostra a disposição destas propriedades no município.

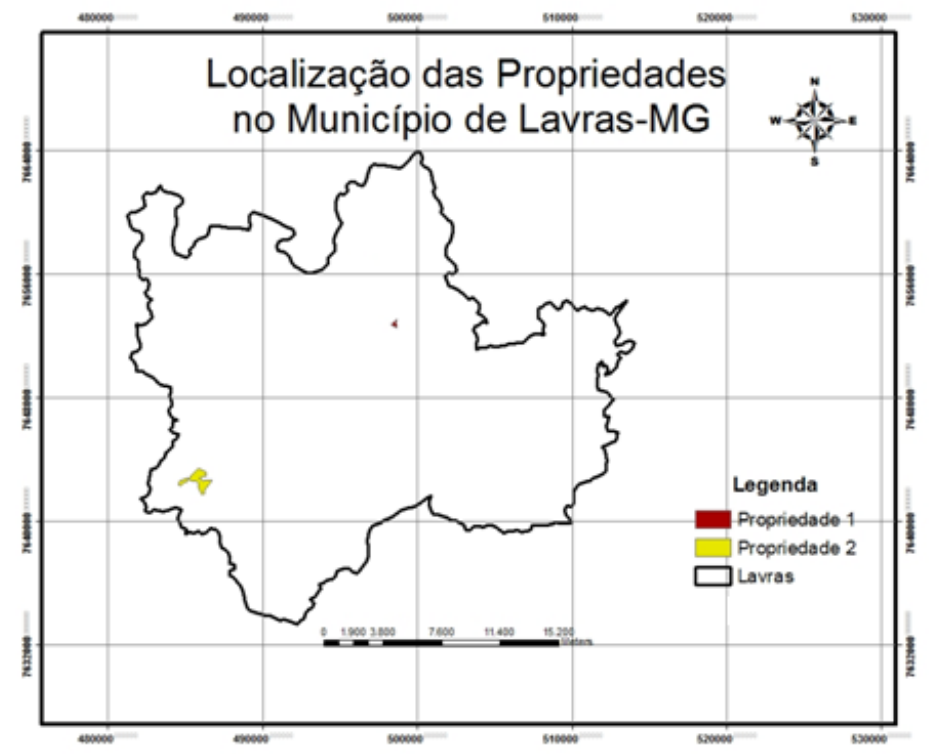

Figura 01: Mapa da localização das propriedades no Município

Fonte: Elaborado pela autora.

A análise das imagens foi visual, e permitiu averiguar que as propriedades 1 e 2 possuem porções de área cobertas por vegetação nativa.

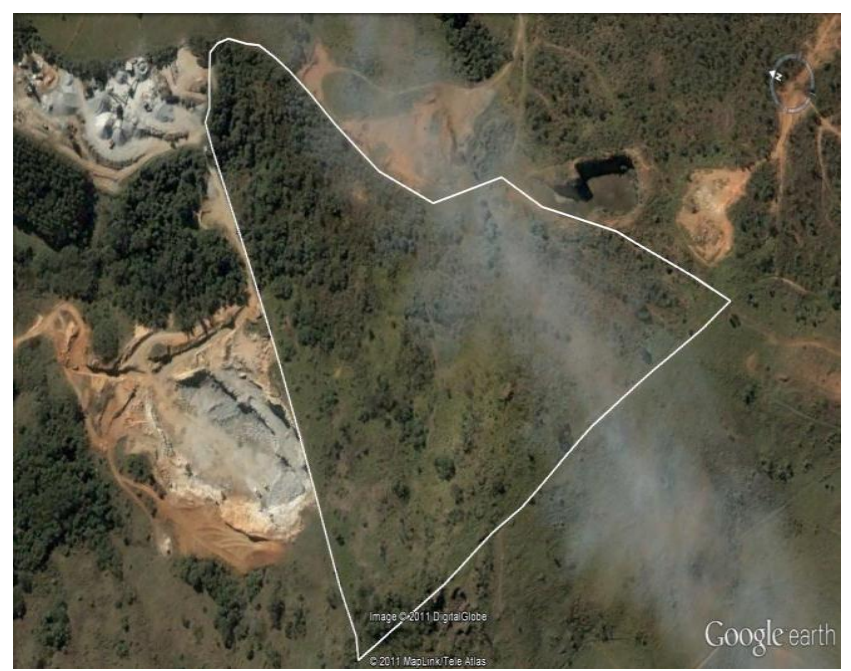

Figura 02: Propriedade 1 - Classe I

Fonte: Google Earth, 2003. 
A propriedade 1 parece estar abandonada, pois não foi possível localizar nenhum tipo de atividade na área (Figura 02). Foi encontrada vegetação nativa como esperado, porém é possível observar que a mesma foi extremamente explorada, tendo boa parte de seu estoque de madeira retirado. O raleamento excessivo da vegetação comprova que não foi utilizado nenhum tipo de plano de manejo para a exploração.

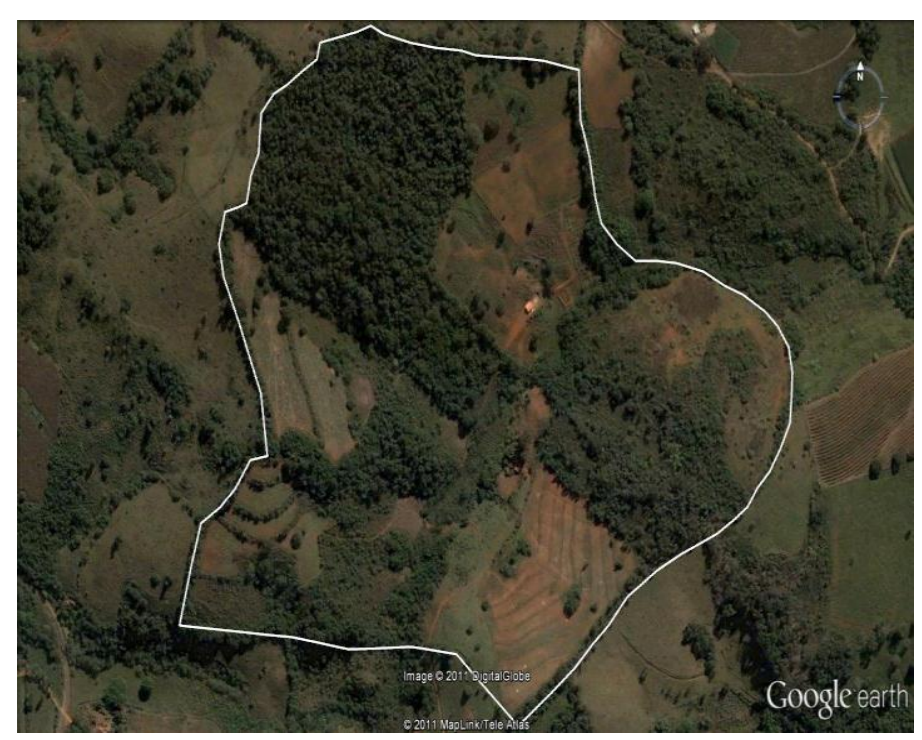

Figura 03: Propriedade 2 - Classe II

Fonte: Google Earth, 2003.

A Reserva Legal da Propriedade 2 foi averbada em duas glebas, o que foi possível confirmar com as imagens (Figura 3). A propriedade realmente possui duas áreas com grande parte coberta por vegetação nativa. A gleba superior está muito bem conservada e densa como esperado, já a outra gleba apresenta grande parte da vegetação explorada.

Com essas imagens foi possível calcular a área das propriedades e estimar a área da RL visualizada. O cálculo foi preciso apenas na Propriedade 2, pois esta possuía em seu registro as coordenadas de sua RL. Já o registro da propriedade 1 não tinha as coordenadas de sua RL, dificultando assim o seu cálculo, logo, nessas duas foi feita uma estimativa a partir da análise visual das mesmas.

As figuras 04 e 05 mostram estas áreas representadas em mapas. Nota-se que houve divergência entre a área registrada em cartório e a área encontrada com auxílio das imagens. Esta diferença pode ser explicada pelo erro na coleta nos pontos georreferenciados ou até mesmo por um erro nas imagens. 


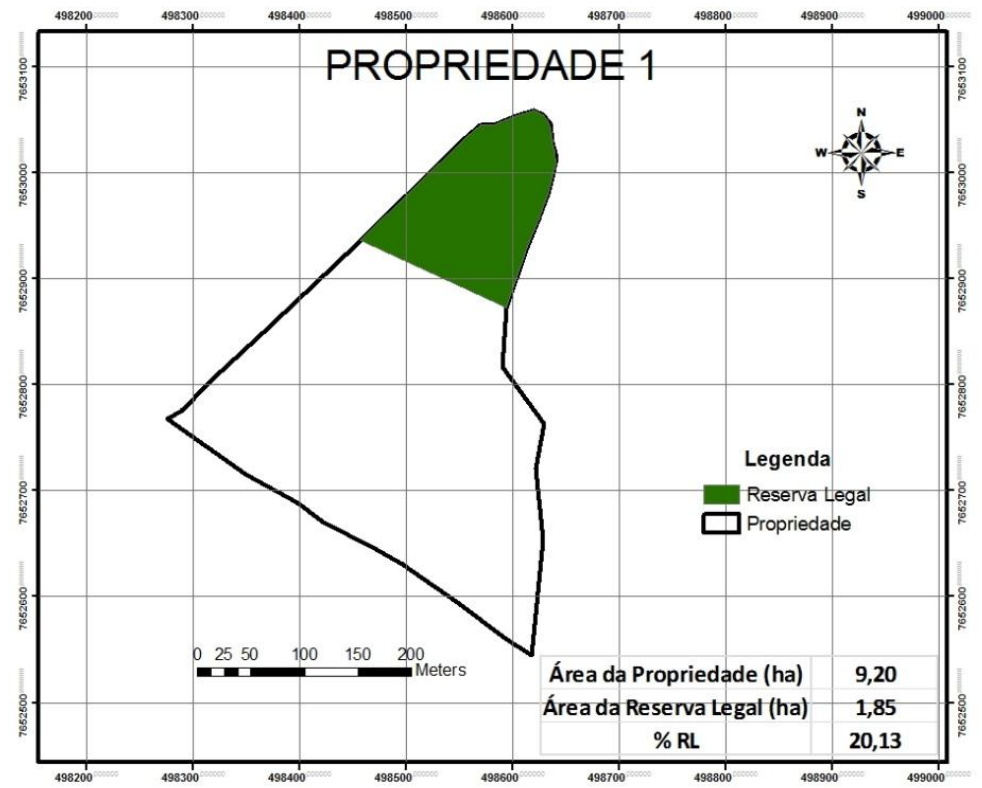

Figura 04: Mapa representativo da propriedade 1 Fonte: Elaborado pela autora.

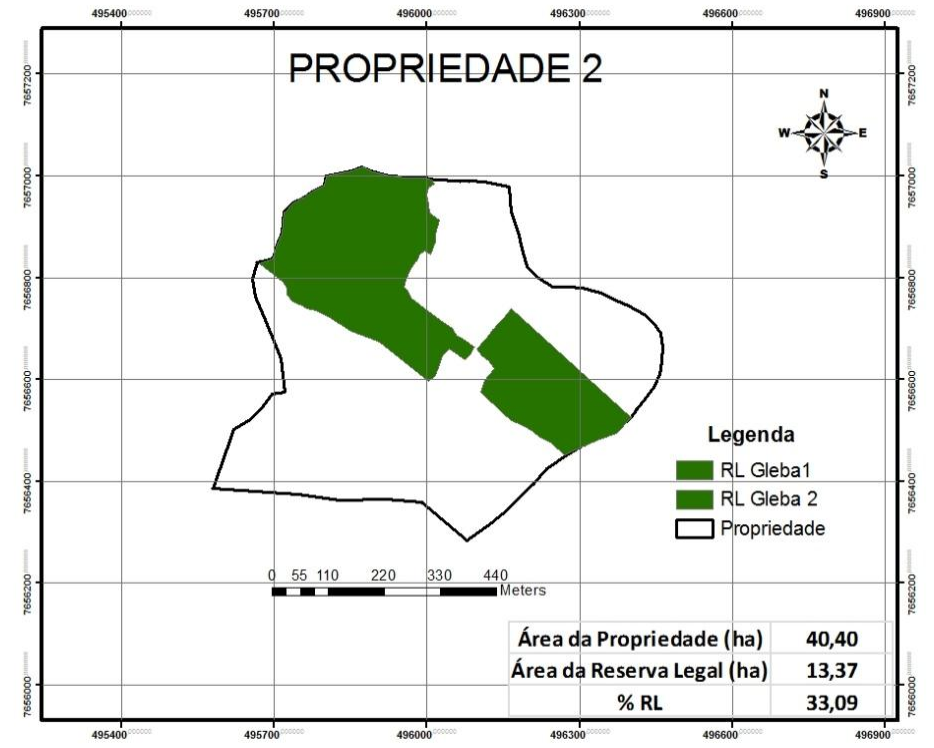

Figura 05: Mapa representativo da propriedade 2 Fonte: Elaborado pela autora.

Percebe-se que se todas as propriedades tivessem as coordenadas georreferenciadas bem delimitadas, além da Reserva Legal devidamente legalizada, a fiscalização poderia ser feita por meio das imagens pelo órgão ambiental competente, o que facilitaria o serviço e reduziria custos. 


\section{CONCLUSÃO}

Foram registradas no Cartório de Registro de Imóveis do município de Lavras - MG 1625 propriedades entre os anos 2000 e 2010, sendo que apenas 31,5\% possuem Reserva Legal averbada, o que demonstra a falta de fiscalização e de incentivos para regularização das mesmas.

Entre as propriedades levantas com área de até 120 hectares, apenas 30,52\% possuem averbação da $R L$ em cartório. Sendo assim, os pequenos produtores deveriam ser estimulados por programas ambientais a regularizarem suas propriedades, visto que essas áreas são essenciais para se manter o meio ambiente equilibrado.

As imagens de satélite mostraram que as propriedades selecionadas possuem as áreas de reserva legal na área da forma como foram averbadas em cartório.

\section{REFERÊNCIAS BIBLIOGRÁFICAS}

BORGES, L. A. C.; REZENDE, J. L. P.; COELHO JÚNIOR, L. M. . Áreas de Proteção Ambiental no Interior de Propriedades Rurais - APP e RL. In: Congresso Internacional de Direito Ambiental, 2009, São Paulo. Direito Ambiental, mudanças climáticas e desastres: impactos nas cidades e no patrimônio cultural. São Paulo: Imprensa Oficial do Estado de São Paulo, 2009. v. 2. p. 397-412.

BORGES, L.A.C; REZENDE, J.L.P. Áreas protegidas no Interior de Propriedades Rurais: A Questão das APP e RL. In: Floresta e Ambiente (FLORAM), v.18, n.2, p 210 - 222, 2011.

BRASIL. Lei no 12.651, de 25 de maio de 2012: Dispõe sobre a proteção da vegetação nativa; altera as Leis no 6.938, de 31 de agosto de 1981, 9.393, de 19 de dezembro de 1996, e 11.428, de 22 de dezembro de 2006; revoga as Leis nㅇ 4.771, de 15 de setembro de 1965, e 7.754, de 14 de abril de 1989, e a Medida Provisória no 2.166- 67, de 24 de agosto de 2001; e dá outras providências. Disponível em: http://www.planalto.gov.br/ccivil_03/_Ato20112014/2012/Lei/L12651.htm. Acesso em: 15 set. 2012.

BRASIL. Medida Provisória no 571, de 25 de maio de 2012. Altera a Lei no 12.651, de 25 de maio de 2012, que dispõe sobre a proteção da vegetação nativa; altera as Leis nos6.938, de 31 de agosto de 1981, 9.393, de 19 de dezembro de 1996, e 11.428, de 22 de dezembro de 2006; revoga as Leis nos 4.771, de 15 de setembro de 1965, e 7.754, de 14 de abril de 1989, e a Medida Provisória no 2.166-67, de 24 de agosto de 2001. Disponível em: http://www.planalto.gov.br/ccivil_03/_Ato2011-2014/2012/Mpv/571.htm. Acesso em: 16 set. 2012. 
CAMPOS, J. B.; COSTA FILHO, L. V.; NARDINE,M. M. Recuperação da reserva legal e a conservação da biodiversidade. Cadernos de Biodiversidade, v.3, n.1, p.1-3, 2002.

FERREIRA, D.S. Reserva Legal na Legislação Brasileira: Viabilidade de implementação em áreas habitadas por populações tradicionais e áreas protegidas. In: Congresso Internacional de Direito Ambiental, 2009, São Paulo. Direito Ambiental, mudanças climáticas e desastres: impactos nas cidades e no patrimônio cultural. São Paulo: Imprensa Oficial do Estado de São Paulo, 2009. v. 2.p.267-276.

FILHO,L.G.F. Períodos e fases do direito ambiental no Brasil. São Paulo: Ribeirão Preto,2010. Disponível em: <http://flavionogueira.wordpress.com/meio-ambiente/periodos-e-fases-do-direitoambiental-no-brasil>. Acesso em: 30 de outubro 2011.

IPEA. Instituto de Pesquisa Econômica Aplicada. Código Florestal: Implicações do PL 1876/99 nas Áreas de Reserva Legal. Comunicados do IPEA n 96. Brasília, IPEA. 2011. 23p

RAMOS-FILHO, L. O.; FRANCISCO, C.E.S. Legislação florestal, sistemas agroflorestais e assentamentos rurais em São Paulo: restrições ou oportunidades? In: CONGRESSO BRASILEIRO DE SISTEMAS AGROFLORESTAIS, 5., 2005, Curitiba. Anais. Colombo: Embrapa, 2004. p.211-213.

SERAFINI, D. E. Reserva legal e função social da propriedade. Disponível em: <http://www.abpr.com.br/artigos/ler/1>. Acesso em: 03 de novembro 2011.

SILVA, J.A.A.;; NOBRE, A.D.; MANZATTO, C.V.; JOLY, C.A.; RODRIGUES, R.R.; SKORUPA, L.A.; NOBRE, C.A.; AHRENS, S.; MAY, P.H.; SÁ, T.D.A. ; CUNHA, M.C.;RECH FILHO, E.L. O Código Florestal e a Ciência: contribuições para o diálogo. São Paulo: Sociedade Brasileira para o Progresso da Ciência, SBPC. Academia Brasileira de Ciências, ABC. 2011. 124 p.

SILVA, J.M.C. da, CASTELETI, C.H.M. Status of the Biodiversity of the Atlantic Forest of Brazil. In: Galindo-Leal, C., Câmara, I.G. (Eds.), The Atlantic Forest of South America: Biodiversity Status, Threats, and Outlook. CABS \& Island Press, Washington, 43-59, 2005.

SILVA, J.M.C. da; SOUZA, M.C. de; CASTELLETTI, C.H.M., Areas of endemism for passerine birds in the Atlantic Forest, South America. Global Ecology and Biogeography, 13, 85-92, 2004.

TRENNEPOHL, T. Direito Ambiental. 4ed. Salvador: JusPodivm, 2009. P209-218. 